$\begin{array}{ll}\text { RefNum } & \text { JIASS-43534 } \\ \text { Manuscript Category } & \text { Movement and Training Science } \\ \text { Manuscript Type } & \text { Original Research } \\ \text { Received } & 08.08 .2019 \\ \text { Accepted } & 30.08 .2019 \\ \text { Corresponding Author } & \text { Nihat Sarıalioğlu[nihat.sarialioglu@giresun.edu.tr] / https://orcid.org/0000-0002-0914-7338 }\end{array}$

\title{
ANALYSIS OF THE RELATIONSHIP BETWEEN PROPRIOCEPTIVE SENSORY FUNCTIONS AND BODY MASS INDEX PARAMETERS OF FOOTBALL AND VOLLEYBALL PLAYERS
}

\author{
Nihat Sarıalioğlu \\ ${ }^{1}$ Department of Physical Education and Sports, Giresun University, Giresun, Turkey.
}

\section{Abstract}

The aim of this study was to examine the relationship between proprioceptive sensory functions and body mass index parameters of football and volleyball players. 16 male football players and 16 male volleyball players, whose average age was 21,4 years, voluntarily participated in this research. In this study, body mass indexes (BMI) were figured out by measuring height and body weight (BW) and proprioceptive sense functions were measured by using TechnoBody PK252 isokinetic balance system measurement device. Balance parameters were recorded as stability index (SI), average force variance (AFV) and average track error (ATE). In the study findings, it was observed that there was no meaningful correlation between the parameters for football players, though there was a negative meaningful correlation between BW and BMI values and ATE and SI values for volleyball players $(p<0,05)$. Although there was not a difference between research groups' proprioceptive sense functions and BMI values, there was a meaningful difference between groups' body height and BW values in the course of comparing the groups. According to these results, it could be said that there was a correlation between some anthropometric data (BW, BMI) and proprioceptive sense functions. However, it is considered that the number of similar studies should be increased in order to reach a final judgement.

Key words: BMI, Football Players, Proprioceptive, Volleyball Players

\section{INTRODUCTION}

The basic component of human life is body movement. Most of the daily activities are related to physical movement and a coordinated body is critical for sporting success (Goble, 2010). In recent years the concept of proprioception has attracted attention due to its effects on performance and coordination in sports.

Proprioception is the general name of the process of creating responses in which the central nervous system of the joints, limbs, ligaments, organelles is detected and kept in the safest state (Kaynak et al., 2015). This automatic sensitivity mechanism that sends messages through the central nervous system in the body allows the body to process information from various stimuli and special sensory receptors in the muscles, joints and connective tissues and turn this information into action. Balance or the body's ability to correct itself requires robust proprioceptive feedback (Duzgun et al., 2011). Proprioceptive function is an important component of postural control (Wang et al., 2008).

Body composition and body mass index (BMI) is one of the subjects that are emphasized in terms of sport competition and performance. The body composition, which is known to have significant effects on athletic performance in sport, 12 
properties (Andreoli et al., 2003). BMI, which is an important part of body composition, is generally calculated by dividing body weight (BW) by the square of the body height in meters (Stensland \& Margolis, 1990).

The aim of this study was to investigate the relationship between proprioceptive sensory abilities and BMI values that are known to have significant effects in sports.

\section{METHODS}

\section{Study Group}

16 male football players and 16 male volleyball players between the ages $18-28$, who have been playing in a certified team for the last five years and have not been exposed to a sporting injury requiring surgery in the last year and whose average age was 21,4 years, participated in the study voluntarily.

Height and body weight measurements

Height $(\mathrm{H})$ measurements of the subjects

were measured with wall-mounted holtain stadiometer and body weight (BW) measurements were measured with tanita MC-580 body analyzer. Body mass index (BMI) was calculated by dividing the $\mathrm{kg}$ of body weight by the square of the height measurement $\left(\mathrm{kg} / \mathrm{m}^{2}\right)$.

\section{Data Collection}

CSMI TecnoBody PK-252 isokinetic balance system measuring instrument was used to determine proprioceptive sensory values. Measurements were performed in 30 seconds with difficulty level 10 by multiaxial proprioceptive assessment module as both feet. Balance parameters were recorded as stability indicator (SI), average force variance (AFV) and average tracking error (ATE) (Goktepe \& Gunay, 2016).

Data Analysis

The data were evaluated by using SPSS software, first with normality test, then with pearson correlation and independent sample $\mathrm{t}$ tests, and the results were analyzed statistically.

\section{RESULTS}

Descriptive statistics of the football players and volleyball players participating in the research were given in Table 1.

Table 1. Descriptive statistics of research groups

PARAMETERS

FOOTBALL

VOLLEYBALL

\begin{tabular}{|c|c|c|c|c|c|c|}
\hline & $\mathbf{n}$ & $\overline{\mathbf{X}}$ & SD & $\mathrm{n}$ & $\overline{\bar{X}}$ & SD \\
\hline ATE & \multirow{6}{*}{16} & 68.31 & 31.26 & \multirow{6}{*}{16} & 66.94 & 14.96 \\
\hline AFV & & 2.97 & 4.89 & & 1.73 & 1.34 \\
\hline SI & & 1.77 & 1.01 & & 2.00 & 0.75 \\
\hline $\mathbf{H}$ & & 177.88 & 5.03 & & 188.00 & 7.99 \\
\hline BW & & 72.88 & 6.60 & & 82.81 & 11.08 \\
\hline BMI & & 23.04 & 1.93 & & 23.41 & 2.68 \\
\hline
\end{tabular}

When the descriptive statistics of the research groups are examined in Table 1, the average values of proprioceptive function values were found to be ATE 68.31, AFV 2.97, SI 1.77 in football players and ATE 66.94, AFV 1.73, SI 2.00 in volleyball players and for average body anthropometric values they were found to be $\mathrm{H} 177.88$, BW 72.88, BMI 177.88 in football players and $\mathrm{H} 188.00$, BW 82.81 , BMI 23.41 in volleyball players. 
Table 2. Correlation analysis of the relationship between height, weight, bmi values and proprioceptive sensory values

\begin{tabular}{cccccccc}
\multirow{2}{*}{ PARAMETERS } & \multicolumn{3}{c}{ CORRELATION } & \multicolumn{3}{c}{ VOTBALL } & \multicolumn{3}{c}{ VOLLEYBALL } \\
\cline { 2 - 8 } & & ATE & AFV & SI & ATE & AFV & SI \\
\hline \multirow{2}{*}{ HEIGHT } & $\mathbf{r}$ & -0.29 & 0.16 & -0.08 & -0.24 & 0.21 & -0.13 \\
\cline { 2 - 8 } & $\mathbf{p}$ & 0.29 & 0.55 & 0.76 & 0.36 & 0.44 & 0.63 \\
\hline \multirow{2}{*}{ BW } & $\mathbf{r}$ & -0.22 & 0.34 & 0.14 & $\mathbf{- 0 . 6 9 8 * *}$ & 0.13 & $\mathbf{- 0 . 6 3 6}^{* *}$ \\
\cline { 2 - 8 } & $\mathbf{p}$ & 0.42 & 0.19 & 0.61 & $\mathbf{0 . 0 0}$ & 0.62 & $\mathbf{0 . 0 1}$ \\
\hline \multirow{2}{*}{ BMI } & $\mathbf{r}$ & -0.05 & 0.26 & 0.19 & $\mathbf{- 0 . 6 4 6 ^ { * * }}$ & 0.01 & $\mathbf{- 0 . 6 4 5 ^ { * * }}$ \\
\cline { 2 - 8 } & $\mathbf{p}$ & 0.87 & 0.34 & 0.48 & $\mathbf{0 . 0 1}$ & 0.97 & $\mathbf{0 . 0 1}$
\end{tabular}

$(* * \mathrm{p}<0.05)$.

When Table 2 was examined, no significant relationship was found between the parameters in football players. In volleyball players, it was seen that there was a significant negative correlation between BW, BMI values and ATE, SI values.

Table 3. Analysis results of differences between test parameters of football and volleyball players

\begin{tabular}{ccccccc} 
& ATE & AFV & Si & HEIGHT & BW & BMI \\
\hline $\mathbf{t}$ & 0.09 & 0.02 & 0.34 & $\mathbf{0 . 0 8 8}^{* *}$ & $\mathbf{0 . 1 1 * *}$ & 0.41 \\
\hline $\mathbf{p}$ & 0.88 & 0.33 & 0.48 & $\mathbf{0 . 0 0}$ & $\mathbf{0 . 0 0}$ & 0.66 \\
$(* * \mathrm{p}<0.05)$. & & & & & &
\end{tabular}

When Table 3 was viewed, it was seen that proprioceptive sensory and BMI values did not differ between the study groups, but there was a significant difference between the height and BW values between the groups.

\section{DISCUSSION AND CONCLUSION}

According to the findings of the study, the average values of the proprioceptive function values of the research groups were found as ATE 68.31, AFV 2.97, SI 1.77 in football players and ATE 66.94, AFV 1.73, SI 2.00 in volleyball players. The average values of body anthropometric measurements were found to be as height 177.88 , BW 72.88, BMI 23.04 for footballers and height 188.00, BW 82.81, BMI 23.41 for volleyball players. Karakas et al. (2011) in a study of the average BMI values of football players found the average as 23,26 . Goral et al. (2012) in the study of the average values of football players stated the values as height 176.5, BW 73.4, BMI 23.55. Aslan et al. in the study of volleyball players BMI values found the average as 24.35 . In their study, Con et al. (2012) found that the average BMI value of volleyball players was 23.4. Ergin and Yucel (2011) found the average values of volleyball players in their studies as 189.5, BW 77.2 and BMI 21.5. In this study and related studies, anthropometric values were found to be normal and similar.
In the correlation analysis between the anthropometric values and proprioceptive sensory values in the study groups, no significant relationship was found between the parameters in football players, and there was a significant negative correlation between BW and BMI values and ATE and SI values in volleyball players $(* * p<0.05)$. In analysis results of the differences between the groups in all parameters, proprioceptive sensory and BMI values were not different between the study groups, while there was a significant difference between the groups in height and BW values $(* * p<0.05)$.

When similar studies were examined, Tabrizi and Sabrestani (2013) stated that anthropometric properties affected dynamic balance in a study conducted by athletes from different branches. Greve et al. (2007) and Ku et al. (2012) reported a significant relationship between BMI and postural balance. Arabaci et al. (2009) reported that there was a negative correlation between BMI and agility in taekwondo athletes 
and also that the ratio of BMI, height and weight of athletes affected the skill properties. Wang et al. (2008) and Morano et al. (2011) stated that obesity decreases postural capacity and has negative effects on motor performance. Blaszczyk et al. (2009) stated that BW and BMI had a significant relationship with dynamic stability. Hogstrom et al. (2012) found that body composition showed a significant relationship with physical performance in adolescents. Gribble et al. (2015) reported that there was a significant relationship between BMI and forward deviation in a study with football players.

Kejonen et al. (2003) found that ankle function showed a significant relationship with BMI. Nikolaidis (2013) found that BMI was related to physical fitness in female volleyball players, and Dane et al. (2002) found that it was associated with sports injuries. Medeiros et al. (2016) emphasized that reduction of fat mass percentage in paralympic athletes was important in improving swimming performance. Mermier et al. (1997) stated that to be superior in sport climbing, a climber must have special anthropometric properties. Erdem et al. (2015) reported that there was a significant relationship between BMI and ball agility in a study on football players. Lopez et al. (2012) emphasized that motor skills showed a negative correlation with BMI in childhood and adolescence.

Similar studies in terms of postural control, physical fitness and performance are in parallel with this study.

It has been proven in many studies that dynamic and static postural stability capabilities are important factors for sporting performance and success. According to the results of this study which examined the relationship between proprioceptive sensory abilities and some anthropometric data which is an important component of postural control, it can be said that BW and BMI are associated with proprioceptive sensory functions in athletes. However, it can be concluded that the number of similar studies should be increased in order to reach a final judgment and that the lack of consideration of muscle mass size compared to sedentary individuals may cause errors when interpreting BMI values in athletes.

\section{REFERENCES}

Medeiros, R.M., Alves, E.S., Lemos, V.A., Schwingel, P.A., Da-Silva, A., Vital, R. et al. (2016) Assessment of body composition and sport performance of brazilian paralympic swim team athletes. Journal of Sport Rehabilitation 25(4), 364-70. doi.org/10.1123/jsr.20150036 .

Goktepe, M. and Gunay, M. (2016) The acute effects of dynamic warm up on static balance and proprioceptive sense in young soccer players. SPORMETRE the Journal of Physical Education and Sport Sciences. 14(2), 213-224. doi.org/10.1501/Sporm_0000000298.

Erdem, K., Çaglayan, A., Korkmaz, O., Kızılet, T. and Ozbar, N. (2015) The evaluation of body mass index, balance and agility features of amateur soccer players according to their positions. International Journal of Sport, Exercise \& Training Sciences 1(2), 95-103.

Aslan, C., Koc, H. and Karakollukcu, M. (2015) Determination of selected physical, physiological and motoric characteristics of a volleyball team in Turkish Men's 1st Volleyball League. Inonu University, Journal of Physical Education and Sport Sciences, 2015, 2(3), 1-13.

Kaynak, H., Altun, M., Ozer, M. and Akseki, D. (2015) Proprioception in sport and its relations with hot and cold applications. CBU Journal of Physical Education and Sport Sciences 10(1), 10-35.

Tabrizi, H.B., Abbasi, A. and Sarvestani, H.J. (2013) Comparing the static and dynamic balances and their relationship with the anthropometrical characteristics in the athletes of selected sports. Middle-East Journal of Scientific Research 15(2), 216-21. doi.org/10.5829/ idosi.mejsr.2013.15.2.7426.

Nikolaidis, P.T. (2013) Body mass index and body fat percentage are associated with decreased physical fitness in adolescent and adult female volleyball players. Journal of Research in Medical Sciences 18, 22-6.

Ku, P.X., Abu-Osman, N.A., Yusof, A. and WanAbas. W.A.B. (2012) Biomechanical evaluation of the relationship between postural control and body mass index. Journal of Biomechanics 45(9), 1638-1642. doi. org/10.1016/j.jbiomech.2012.03.029.

Hogstrom, G.M., Pietila, T., Nordstrom, P. and Nordstrom, A. (2012) Body composition and performance: influence of sport and gender among adolescents. Journal of Strength and Conditioning Research 26(7), 1799-1804. doi.org/10.1519/ JSC.0b013e318237e8da.

Gribble, P., Brigle, J., Pietrosimone, B., Pfile, K. and Webster, K. (2012) Intrarater reliability of the functional movement screen. The Journal of Strength \& Conditioning Research 27(4), 978-981. doi. org/10.1519/JSC.0b013e31825c32a8. 
Goral, K., Saygin, O. and Babayigit, I.G. (2012) Examining of reaction time of professional soccer players according to their playing positions, Selçuk University Journal of Physical Education and Sport Science 14(1), 5-11.

Con, M., Akyol, P. and Tural, E (2012) The effect of volleyball players' flexibility and body fat percentage values on vertical jump performance. Selçuk University Journal of Physical Education and Sport Science 14(2), 202-207.

Lopes, V.P., Stodden, D.F., Bianchi, M.M., Maia, J.A.R. and Rodrigues, L.P. (2012) Correlation between BMI and motor coordination in children. Journal of Science and Medicine in Sport 15(1), 38-43. doi.org/10.1016/j. jsams.2011.07.005.

Karakas, S., Yildiz, Y., Kose H., Temocin, S. and Kizilkaya, K. (2011) The effects of team, position and pkysical feature factors on body composition in professional and amateur soccer players. Meandros Medical and Dental Journal 12(1), 63 -69.

Ergin, E. and Bereket, Y.S. (2011) Acute effects of stretching exercise modalities on upper and lower extremity strength parameters. Turkish Journal of Sports Medicine 46(4), 145-153.

Duzgun, I., Kanbur, N.O., Baltaci, G. and Aydın, T. (2011) Effect of Tanner stage on proprioception accuracy. The Journal of Foot and Ankle Surgery 50(1), 11-5. doi.org/10.1053/j.jfas.2010.09.002.

Morano, M., Colella, D., Robazza, C., Bortoli, L. and Capranica, L. (2011) Physical self-perception and motor performance in normal-weight, overweight and obese children. Scandinavian Journal of Medicine \& Science in Sports 21(3), 465-73. doi.org/10.1111/j.16000838.2009.01068.x

Arabaci, R., Gorgulu, R. and Catikkas, F. (2010) Relationship between agility and reaction time, speed and body mass index in taekwondo athletes. Sport Sciences 5(2), 71-77.

Goble, D.J. (2010) Proprioceptive acuity assessment via joint position matching: from basic science to general practice. Physical Therapy | Oxford Academic - Oxford Journals 90(8), 1176-1184. doi.org/10.2522/ ptj.20090399.

Blaszczyk, J.W., Cielinska-Swider, J., Plewa, M., Zahorska-Markiewicz, B. and Markiewicz A. (2009) Effects of excessive body weight on postural control. Journal of Biomechanics 42(9), 1295-1300. doi. org/10.1016/j.jbiomech.2009.03.006.

Wang, L., Li, J.X., Xu, D.Q. and Hong, Y.L. (2008) Proprioception of ankle and knee joints in obese boys and nonobese boys. Medical Science Monitor 14(3), 129-135.
Greve, J., Alonso, A., Bordini, A.C. and Camanh, G.L. (2007) Correlation between body mass index and postural balance. Clinics 62(6), 717-720. doi. org/10.1590/S1807-59322007000600010.

Andreoli, A., Melchiorri, G., Brozzi, M., Di-Marco, A., Volpe, SL., Garofano, P. et al. (2003) Effect of different sports on body cell mass in highly trained athletes. Acta Diabetologica 40(1), 122-125.

Kejonen, P., Kauranen, K. and Vanharanta, H. (2003) The relationship between anthropometric factors and bodybalancing movements in postural balance. Archives of Physical Medicine and Rehabilitation 84(1), 17-22. doi. org/10.1053/apmr.2003.50058.

Dane, S., Can, S. and Karsan, O. (2002) Relations of Body Mass Index, body fat, and power of various muscles to sport injuries. Perceptual and Motor Skills 95(1), 329-334. doi.org/10.2466/pms.2002.95.1.329.

Mermier, C.M., Robergs, R.A., McMinn, S.M. and Swan, J.G. (1997) Energy expenditure and physiological responses during indoor rock climbing. British Journal of Sports Medicine 31(3), 224-228.

Stensland, S.H. and Margolis, S. (1990) Simplifying the calculation of body mass index for quick reference. Journal of the American Dietetic Association 90(6), 856. 